\title{
RESPECT OR RESECT: A SINGLE STRATEGY DOES NOT FIT ALL
}

\author{
Antonio Calafiore ${ }^{1}$, Gaetano Castellano ${ }^{2}$, Stefano Guarracini ${ }^{3}$, Massimo Di Marco ${ }^{4}$, \\ Antonio Totaro ${ }^{2}$, Cosimo Sacra $^{2}$, Kostas katsavrias $^{5}$, and Michele Di Mauro ${ }^{6}$ \\ ${ }^{1}$ John Paul II Foundation for Research and Treatment \\ ${ }^{2}$ Gemelli Molise \\ ${ }^{3}$ Private Hospital Pierangeli Srl \\ ${ }^{4}$ Santo Spirito Hospital \\ ${ }^{5}$ Henry Dunant Hospital Center \\ ${ }^{6}$ Maastricht UMC+
}

December 30, 2020

\begin{abstract}
Mitral valve (MV) repair for mitral regurgitation (MR) due to posterior leaflet (PL) prolapse is achieved nowadays with a great success rate and a good survival, similar, in certain subgroups. In this paper, Sakaguchi et al describe their results in two groups of patients with PL prolapse. Some patients underwent resection (resection group) and others chordal replacement with/out limited resection (respect group). Results were similar in terms of survival and MR recurrence. Our goal is to eliminate, as much as possible, MR when a patient with degenerative MR is operated on. Reduction of the mitral orifice and consequently an increase of the transmitral gradient is the rule. MV repair for degenerative MR provides great results, but there is not a single surgical technique. A close evaluation of the anatomical findings will allow us to choose the best strategy for the individual patient. An open mind is the most important characteristic that a surgeon should have to repair a prolapsing PL without residual regurgitation and dangerous gradients.
\end{abstract}

\section{RESPECT OR RESECT: A SINGLE STRATEGY DOES NOT FIT ALL}

Antonio M. Calafiore (1), MD, Gaetano Castellano (1), Stefano Guarracini (2), MD, Massimo Di Marco (3), MD, Antonio Totaro (1), MD, Sacra Cosimo (1), MD, Kostas Katsavrias (4), Michele Di Mauro (2,5), PhD, MD.

1. Department of Cardiovascular Sciences, Gemelli Molise, Campobasso, Italy

2. Department of Cardiology, "Pierangeli" Hospital, Pescara, Italy

3. Department of Cardiology, "Santo Spirito" Hospital, Pescara, Italy

4. Department of Cardiac Surgery, Henry Durant Hospital, Athens, Greece

5. Cardio-Thoracic Surgery Unit, Heart and Vascular Centre, Maastricht University Medical Centre (MUMC), Cardiovascular Research Institute Maastricht (CARIM).

\section{Corresponding author}

Antonio M. Calafiore, MD

Department of Cardiovascular Diseases

Gemelli Molise 
Largo A. Gemelli 1, 86100

Campobasso, Italy

email:am.calafiore@gmail.com

Abstract

Mitral valve (MV) repair for mitral regurgitation (MR) due to posterior leaflet (PL) prolapse is achieved nowadays with a great success rate and a good survival, similar, in certain subgroups.

In this paper, Sakaguchi et al describe their results in two groups of patients with PL prolapse. Some patients underwent resection (resection group) and others chordal replacement with/out limited resection (respect group). Results were similar in terms of survival and MR recurrence.

Our goal is to eliminate, as much as possible, MR when a patient with degenerative MR is operated on. Reduction of the mitral orifice and consequently an increase of the transmitral gradient is the rule.

MV repair for degenerative MR provides great results, but there is not a single surgical technique. A close evaluation of the anatomical findings will allow us to choose the best strategy for the individual patient. An open mind is the most important characteristic that a surgeon should have to repair a prolapsing PL without residual regurgitation and dangerous gradients.

Mitral valve (MV) repair for mitral regurgitation (MR) due to posterior leaflet (PL) prolapse is achieved nowadays with a great success rate and a good survival, similar, in certain subgroups, to that of the normal population ${ }^{1}$. Carpentier et al. ${ }^{2}$ defined the terms and put the principles which, with some modifications, are still followed by many surgeons. Their vision, along with the concept of annuloplasty ${ }^{3}$ and the advent of artificial chords ${ }^{4}$, are the pillars on which MV repair stands. There is no doubt that nowadays a high percentage of repair can be achieved in specialized centers, but it is as well true that a huge variety of techniques are used to obtain a competent valve. Most of these have only midterm results, often very good, which justify the optimistic prevision for a high long-term patency rate.

In this paper, Sakaguchi et al. ${ }^{5}$ describe their results in two groups of patients with PL prolapse. Some patients underwent resection (resection group) and others chordal replacement with/out limited resection (respect group). Results were similar in terms of survival and MR recurrence. The main difference was a higher ring size and a higher effective orifice area in the respect group. The clinical significance of this finding in the long term was not however explored.

In our opinion, this study raises some issues that should be addressed. Is it really necessary to have a dichotomous approach to PL prolapse? Should we divide ourselves in surgeons who resect and surgeons who respect? Our group, as others, had a progressive and spontaneous transition from resecting to respecting techniques. In 2006 we published a paper ${ }^{6}$ where 41 (29\%) out of 141 patients had no resection. In 2011, another study of ours ${ }^{7}$ reported 60 cases where $39(65 \%)$ had no resection. Finally, in 2014, we described a technique able to correct PL prolapse without using artificial chords even in case of chordal rupture ${ }^{8}$. Nevertheless, there are always cases where an excessively redundant PL needs to be reduced, often with a triangular resection. For these cases, Antunes coined an interesting term: "resect with respect" 9 (Fig. 1). This means that we must have an open mind to obtain the best result for our patients. Artificial chords can be used or not, resection can be performed or not. What is important is the long-term result and the quality of life. Sakaguchi et al. ${ }^{5}$ followed this line given that some of their patients included in the respect group had limited resection, as a result of some common sense applied during surgery.

There is another important point that arises from this paper. Our goal is to eliminate, as much as possible, MR when a patient with degenerative MR is operated on. Reduction of the mitral orifice and consequently an increase of the transmitral gradient is the rule. But to what extent have we to push our technique to minimize this gradient? In other words, should we change technique in order to use a larger ring/band or to eliminate any possible bulky tissue inside the mitral orifice to obtain the lowest gradient? The Authors seem to prefer the respect technique due to a (modestly) reduced gradient and the (slightly) higher size of the 
device used for annuloplasty. This is comprehensible, but the data do not reflect the Authors' point of view. It is true that the mean mitral effective orifice area is higher in the respect group compared to the resection group (1.86 \pm 0.48 vs $\left.1.66 \pm 0.47 \mathrm{~cm}^{2}, \mathrm{p}<0.001\right)$. However, around $25 \%$ of patients in the respect group and $40 \%$ of patients in the resection group had a MV area $<1.5 \mathrm{~cm}^{2}$, and severe mitral stenosis (MS) mandates a strict follow-up according to the American and European guidelines ${ }^{10,11}$. Those areas are definitely smaller than usual.

Indeed, induced MS is the other face of the medal of MV repair. This problem is not negligible in an era when MV repair is proposed to asymptomatic, often young and active, patients. MS can be a serious problem in the early period, reflecting the predominance of surgical techniques. It was cause of reoperation either in the operating theatre ${ }^{12}$ or before hospital discharge ${ }^{13}$, being the edge-to-edge technique the predominant cause of early reoperation. In the long term, however, the prevalence of MS as a cause of reoperation seems to be very $\operatorname{rare}^{14}$.

It is difficult to clarify the exact prevalence of this complication. Chan et al. ${ }^{15}$ reported 110 patients who had MV repair for MV prolapse and found that $20 \%$ of patients had a MV area [?]1.5 $\mathrm{cm} 2$, with a mean gradient [?] $5 \mathrm{mmHg}$. This functional pattern was associated with worse hemodynamics, lower exercise capacity and adverse outcomes. In most patients, a complete rigid ring was used. Kawamoto et al. ${ }^{16}$ found that $8 \%$ of their patients had a rest mean transmitral gradient [?] $5 \mathrm{mmHg}$ at discharge, mostly related to a smaller ring size. During follow-up, these patients showed increased tricuspid regurgitation severity, increased pulmonary pressure and a higher onset of atrial fibrillation than patients with lower gradients. Interestingly, even patients where the ring used was true sized can present severe MS. Doi et al. ${ }^{17}$ found that 7 out of 20 patients undergoing stress echocardiography after MV repair with a semirigid true sized ring showed peak gradients at effort [?] $15 \mathrm{mmHg}$. In general, lacking prospective studies, we can speculate that $10 \%$ to $20 \%$ of patients with a good repair are discharged with some significant MS, which can affect the long-term outcome.

The problem exists, but long-term results reported by Sakaguchi et al. ${ }^{5}$ are limited to MR recurrence. We have no idea if the early benefit of a lower gradient and a higher mitral orifice in the respect group translated into a better clinical outcome.

MV repair for degenerative MR provides great results, but there is not a single surgical technique. A close evaluation of the anatomical findings will allow us to choose the best strategy for the individual patient. An open mind is the most important characteristic that a surgeon should have to repair a prolapsing PL without residual regurgitation and dangerous gradients.

\section{REFERENCES}

1. Tomsic A, Hiemstra YL, van der Pas SL, et al. Early and long-term outcomes of mitral valve repair for Barlow's disease: a single-centre 16-year experience. Interact Cardiovasc Thorac Surg 2018;26:783-9.

2. Carpentier A, Deloche A, Dauptain J, et al. A new reconstructive operation for correction of mitral and tricuspid insufficiency. J Thorac Cardiovasc Surg 1971;61:1-13.

3. Lillehei CW, Gott VL, Dewall RA, Varco RL. Surgical correction of pure mitral insufficiency by annuloplasty under direct vision. J Lancet 1957;77:446-9.

4. Frater RW, Vetter HO, Zussa C, Dahm M. Chordal replacement in mitral valve repair. Circulation 1990;82:IV125-30.

5. Sagakuchi T, Hiraoka A, Totsugawa T, et al. Clinical impact of the repair technique for posterior mitral leaflet repair: resect or respect? J Card Surg, in press.

6. Calafiore AM, Di Mauro M, Iaco AL, et al. Overreduction of the posterior annulus in surgical treatment of degenerative mitral regurgitation. Ann Thorac Surg 2006;81:1310-6.

7. Calafiore AM, Di Mauro M, Iaco AL, et al. Resecting and nonresecting techniques for posterior mitral leaflet prolapse. J Card Surg 2011;26:119-23. 
8. Calafiore AM, Iaco AL, Ibrahim A, et al. A novel and simple technique for correction of posterior leaflet prolapse due to chordal elongation or rupture. J Thorac Cardiovasc Surg 2014;148:1407-12.

9. Antunes MJ. Revisiting posterior mitral leaflet prolapse: Resect, respect, or resect with respect? J Thorac Cardiovasc Surg 2018;155:602-3.

10. Nishimura RA, Otto CM, Bonow RO, et al. 2014 AHA/ACC Guideline for the Management of Patients With Valvular Heart Disease: a report of the American College of Cardiology/American Heart Association Task Force on Practice Guidelines. Circulation 2014;129:e521-643.

11. Baumgartner H, Falk V, Bax JJ, et al. 2017 ESC/EACTS Guidelines for the management of valvular heart disease. European heart journal 2017;38:2739-91.

12. DiBardino DJ, ElBardissi AW, McClure RS, Razo-Vasquez OA, Kelly NE, Cohn LH. Four decades of experience with mitral valve repair: analysis of differential indications, technical evolution, and long-term outcome. J Thorac Cardiovasc Surg 2010;139:76-83.

13. Riegel AK, Busch R, Segal S, Fox JA, Eltzschig HK, Shernan SK. Evaluation of transmitral pressure gradients in the intraoperative echocardiographic diagnosis of mitral stenosis after mitral valve repair. PLoS One 2011;6:e26559.

14. Nishida H, Fukui T, Kasegawa H, Kin H, Yamazaki M, Takanashi S. Causes of repair failure for degenerative mitral valve disease and reoperation outcomes. Eur J Cardiothorac Surg 2018;53:1244-50.

15. Chan KL, Chen SY, Mesana T, Lam BK. Development of Mitral Stenosis After Mitral Valve Repair: Importance of Mitral Valve Area. Can J Cardiol 2017;33:1701-7.

16. Kawamoto N, Fujita T, Fukushima S, et al. Functional mitral stenosis after mitral valve repair for Type II dysfunction: determinants and impacts on long-term outcome. Eur J Cardiothorac Surg 2018;54:453-9.

17. Doi K, Yamano T, Ohira S, Yamazaki S, Numata S, Yaku H. Annuloplasty Ring Size Determines Exercise-Induced Mitral Stenosis Severity after Valve Repair. J Heart Valve Dis 2015;24:744-51. 